Editorial

\title{
Three Inspiring Review Articles on Photobiomodulation: Update 2021
}

\author{
Gerhard Litscher *
}

Research Unit of Biomedical Engineering in Anesthesia and Intensive Care Medicine, Research Unit for Complementary and Integrative Laser Medicine, and Traditional Chinese Medicine (TCM) Research Center Graz, Medical University of Graz, 8036 Graz, Austria; E-Mail: gerhard.litscher@medunigraz.at

* Correspondence: Gerhard Litscher; E-Mail: gerhard.litscher@medunigraz.at

Collection: Trends in Acupuncture and Laser Research and Education

OBM Integrative and Complementary Medicine

2021, volume 6 , issue 2

doi:10.21926/obm.icm.2102018
Received: May 18, 2021

Accepted: May 18, 2021

Published: May 20, 2021

\begin{abstract}
Photobiomodulation (PBM) is an accurate term for an effective and important application of light in medicine (such as in photomedicine). Three review articles of authors from the International Society of Medical Laser Applications (ISLA-Transcontinental) on the topic of PBM with a total of 116 printed pages, published in one renowned journal of molecular sciences with an impact factor of 13.668 , are presented in the current review. The main topics are PBM, probiotics, curcumin, and arthritis. PBM can modulate cellular dysfunctions, trigger self-organization phenomena, and alleviate different diseases.
\end{abstract}

\section{Keywords}

Photobiomodulation; probiotics; curcumin; arthritis; laser; light; integrative and complementary medicine

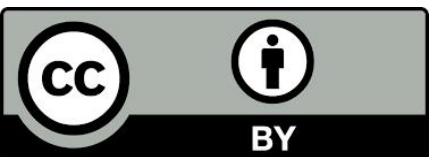

(C) 2021 by the author. This is an open access article distributed under the conditions of the Creative Commons by Attribution License, which permits unrestricted use, distribution, and reproduction in any medium or format, provided the original work is correctly cited. 


\section{Introduction}

The International Society of Medical Laser Applications (ISLA-Transcontinental) has set before itself the goal of not only carrying out pioneering research but also executing the publication of top-quality articles [1]. For instance, during the COVID-19 lockdown, under the first authorship of professor Laura Ailioaie and with the participation of the ISLA President Gerhard Litscher (responsible for Science \& Research) three review articles on the topic of photobiomodulation (PBM) with a total of 116 printed pages were published in one renowned journal of molecular sciences with an impact factor of 13.668. So far, these open-access articles have already been accessed around 5000 times, which is also a significant number for such special review work in such a short time.

\section{Photobiomodulation-Probiotics}

Advantages and perspectives of the so-called applied photobiomics for health are presented in the first publication. Coupled with complex PBM, probiotic interventions could improve immune system activity and cure/save the precious lives of people with immune deficiencies, for example, in successfully tackling the COVID-19 crisis [2].

\section{Photobiomodulation-Curcumin}

Curcumin, a natural product, can be used in certain areas of the human immune system inexpensively and without any side effects. Curcumin and blue PBM could suppress viruses and better control certain diseases by reducing inflammation and the progression of chronic hepatitis. The second article addresses this research question [3].

\section{Photobiomodulation-Arthritis}

Juvenile idiopathic arthritis (JIA) and adult rheumatoid arthritis (RA) are two main groups with chronic joint pain and inflammation, extra-articular manifestations of RA, and a high risk of comorbidities that lead to physical disabilities and can generate high socio-economic pressure worldwide. PBM has proven a good option here too and offered cost-effective advantages over drug therapy with a faster, more positive response to treatment. The third article addresses this question [4].

\section{Discussion and Conclusion}

Light therapy is a very powerful tool in medicine and is extensively used because compared to drugs, it simultaneously targets many cascades of immune system activation. Both PBM and laser acupuncture can perform very delicate tasks in our body in order to modulate cellular dysfunctions, trigger self-organization phenomena, alleviate several diseases, or even cure them under certain circumstances. 


\section{Acknowledgments}

The author of this editorial would like to thank Prof. Laura Marinella Ailioaie from Romania for the excellent cooperation. Parts of this editorial will be published in modified form in Akupunktur \& Aurikulomedizin in volume 47, issue 2, June 2021 [1].

\section{Author Contributions}

The author did all the research work of this editorial.

\section{Funding}

TCM Research Center Graz, Medical University of Graz.

\section{Competing Interests}

The author does not declare any conflict of interest.

\section{References}

1. Weber M, Litscher G. ISLA aktuell: Drei inspirierende Übersichtsarbeiten zur Photobiomodulation. Akupunktur Aurikulomedizin. 2021; 47. in press.

2. Ailioaie LM, Litscher G. Probiotics, photobiomodulation, and disease management: Controversies and challenges. Int J Mol Sci. 2021; 22: 4942.

3. Ailioaie LM, Litscher G. Curcumin and photobiomodulation in chronic viral hepatitis and hepatocellular carcinoma. Int J Mol Sci. 2020; 21: 7150.

4. Ailioaie LM, Litscher G. Molecular and cellular mechanisms of arthritis in children and adults: New perspectives on applied photobiomodulation. Int J Mol Sci. 2020; 21: 6565.

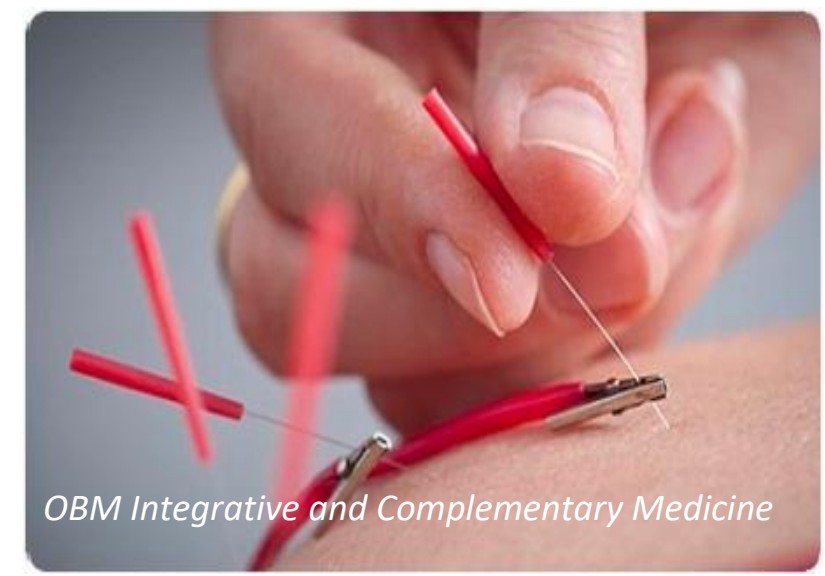

Enjoy OBM Integrative and Complementary Medicine by:

1. Submitting a manuscript

2. Joining in volunteer reviewer bank

3. Joining Editorial Board

4. Guest editing a special issue

For more details, please visit: http://www.lidsen.com/journals/icm 